ÁREA ABIERTA. Vol. 14, $n^{\circ}$ 3. Numero monográfico "Feminismo, estudios sobre mujeres y cultura audiovisual". Noviembre 2014

http://dx.doi.org/10.5209/rev_ARAB.2014.v14.n3.46427

"EL NUEVO CINE DE MUJERES DE LATINOAMÉRICA: OBSERVACIONES EN TORNO A LA POÉTICA TRANSGRESIVA EN 'LA CIÉNAGA' DE LUCRECIA MARTEL”

AUTORA: Uta FELTEN, Universität Leipzig, Alemania

\title{
El nuevo cine de mujeres de Latinoamérica: observaciones en torno a la poética transgresiva en "La ciénaga" de Lucrecia Martel
}

\author{
The New Argentine Women \\ Cinema: The poetics of \\ transgression in Lucrecia Martel's \\ "The swamp"
}




\title{
RESUMEN:
}

El cine de Lucrecia Martel se constituye según nuestro punto de vista como cine de transgresión por excelencia, cine que se complace en transgredir las normas académicas del realismo cinematográfico y del cine de acción tanto como los dispositivos tradicionales del cuerpo, del deseo y de la mirada. La contribución se concentra en el primer largometraje de Lucrecia Martel La ciénaga y trata de poner de relieve algunos de los procedimientos transgresivos principales. Salen a la vista al menos tres estrategias básicas de transgresión: la transgresión radical y voluntaria de las categorías académicas del cine de acción, la subversión de la oposición binaria entre mirada subjetiva y objetiva y la subversión de los dispositivos tradicionales del cuerpo y del deseo.

La ciénaga es una película bekettiana por excelencia, todos parecen esperar algo, pero no pasa nada en absoluto. La ciénaga es el contrario del cine de acción. La acción no existe. En vez de presentarnos una trama lineal con inicio, nudo y desenlace tan habitual en el cine de acción tradicional, Martel rechaza voluntariamente el concepto de trama lineal y nos confronta con una textura visual laberíntica y borgesiana en la que varios senderos se bifurcan sin llevarnos jamás a nigún centro. Martel opta por la mirada frágil y desorientada de una adolescente que mira el mundo. En este contexto La ciénaga también nos ofrece la posibilidad de ser leída como una celebración de la caída de la ley patriarcal.

\section{Palabras clave:}

Cine femenino, Gender, cuerpo, mirada, cine argentino

\begin{abstract}
:
Lucrecia Martel's cinema constitutes in our view a cinema of transgression par excellence, a cinema that transgresses the rules of academic realism and a classical "cinema of action' (Deleuze) as much as the traditional devices of the body, desire and look. The contribution focuses on the first feature by Lucrecia Martel, The swamp and tries to point out some of its major transgressive procedures. We can carve out at least three basic strategies of transgression: the radical and willful transgression of academic categories of a cinema of action, the subversion of the opposition between subjective and objective look and the subversion of traditional devices of desire and the body.

The swamp is the opposite of a cinema of action. Action does not exist. Instead of presenting a linear plot, Martel confronts us with a labyrinthine visual texture in which several paths diverge and never lead us to a center. Martel chooses the fragile and disoriented perspective of a teenager who looks at the world. In this context, The swamp can be read as a celebration of the fall of the patriarchal law.
\end{abstract}

\section{Key words:}

Women Cinema, Argentina, gender, body, gaze. 
Mi responsabilidad es mantener una visión crítica de mi situación de mujer de clase media argentina.

En ese lugar me ubico dentro del cine argentino. Creo que el cine tiene una función política en esos términos.

Lucrecia Martel cit. por Oubiña, 2009: 63

[...] vedere o non vedere il giusto valore delle cose. Michelangelo Antonioni ,2005: 85

Es un cine de vidente, ya no es un cine de acción.

Gilles Deleuze, 1986: 13

\begin{abstract}
A partir de 1990 se manifiesta un boom del cine de mujeres en Latinoamérica. Precursoras de este nuevo cine de mujeres que tiene una propia estética, una propia escritura cinematográfica, un discurso propio de la memoria, una poética transgresiva que se manifiesta en su voluntad radical de re-escribir y re-codificar los dispositivos tradicionales del cuerpo, del género y de la mirada son las directoras mexicanas María de Novara y María Luisa Bemberg, que se hizo conocida a nivel internacional a través de la película sobre la vida de Sor Juana Inés de la Cruz Yo, La Peor de todas (1990), pero que ya había trabajado como directora de cine desde principios de los años setenta.
\end{abstract}

Entre los más importantes países de producción cinematográfica femenina en Latinoamérica son, sin duda, Argentina, México y Brasil, los que tienen una larga tradición cinematográfica. Entre ellos Argentina ha tomado una posición predominante. Reconocidas internacionalmente son directoras como: Albertina Carri con Los rubios (2003), Lucrecia Martel con La ciénaga (2001) y Lucía Puenzo con XXY (2007). La película Los rubios es una película clave del nuevo cine argentino que forma parte de la tradición del cine de la memoria y del cine documental, pero que logra al mismo tiempo introducir un nuevo discurso de auto-reflexión sobre la posibilidad y la imposibilidad de la memoria subjetiva.

La directora argentina Albertina Carri ya cuenta con una gran obra cinematográfica muy compleja y hetereogénea que va desde el drama rural La rabia (2008) hasta la rescritura crítica del discurso pornográfico en Barbie también puede estar triste (2002). En su película Los rubios, premiada en numerosos festivales nacionales e internacionales de cine, Carri reescribe en forma crítica el género de la película historicista y el género de la película documental. El motivo y el hilo conductor de la película es la sensación de vacío omnipresente y radical en la vida de la directora cuyos padres fueron asesinados en la época de la sangrienta dictadura militar en Argentina (1976-1983) y forman parte del gran número de desaparecidos en esa época. 
Albertina Carri, nacida en 1973, explica en sus comentarios autobiográficos que tenía cuatro años cuando los representantes del ejército llegaron a su casa, tomaron a sus padres - dos intelectuales - y los encarcelaron sin razón. En la primera fase, la hija, que vivía con sus abuelos lejos de la ciudad, todavía tenía contacto con los padres que le escribieron cartas desde la cárcel. Después de cierto tiempo se perdieron las huellas de los padres. Los cuerpos nunca fueron encontrados. Los padres de Albertina Carri asesinados en la época de la dictadura militar-período de terrorismo de estado, violencia y represión arbitraria-son dos de los 30.000 desaparecidos, asesinados o torturados hasta la muerte por los líderes militares argentinos en aquel período.

El cine argentino ha intentado durante mucho tiempo hablar de los crímenes de la dictadura empleando el medio cinematográfico como un archivo de la memoria. El discurso de la memoria que desarolla Carri en Los rubios es totalmente innovador por su intento de reflexionar sobre los procedimientos propios de la memoria y sobre la dificultad de arrojar luz sobre los crímenes cometidos durante la dictadura. Una estrategia importante de la nueva narrativa de Carri es la duplicación de su posición como una víctima para crear la posibilidad de un acercamiento intelectual. Por eso buscó a una actriz que desempeñara el papel de Albertina Carri mientras ella misma aparece en la película como directora de cine. Todo este complejo enfoque autorreflexivo permite a los espectadores reflexionar sobre el proceso de la reconstrucción de la memoria.

Otro elemento de innovación se manifiesta en el mismo concepto de la memoria. Recurriendo implícitamente al uso de las posiciones teóricas de memoria de Marcel Proust y Henri Bergson, Carri demuestra que la memoria individual no puede nunca ser coherente y lineal, sino que se compone siempre de fragmentos, rupturas y discontinuidades. Esta concepción de la memoria ya se manifiesta en el título de la película Los rubios. Cuando se pregunta a los vecinos si sabían algo de la familia de los Carri, ellos dicen que se acuerdan de una familia de rubios, de hecho, sólo una de las hermanas, Albertina, era rubia. El título hace referencia a esas lagunas siempre presentes en la memoria que nunca puede ser coherente y completa y exige por eso un discurso autoreflexivo que medita sobre la posibilidad y la imposibilidad de la reconstrucción de la memoria.

Los rubios es sin duda una obra maestra que ha instalado un discurso innovador en el ámbito del cine de memoria hasta ahora existente y ha inaugurado un nuevo tipo de cine político.

Otro ejemplo paradigmático de un nuevo cine político lo constituye el cine de Lucrecia Martel igualmente reconocido internacionalmente. Una de las lecturas más importantes de la premiada película La ciénaga es la lectura política. Aunque no hay una sola referencia directa a la corrupción de la clase política de la era Menem durante toda la película, el título La ciénaga se refiere no solo a nivel semántico al pantano y la podredumbre, sino que se puede leer al mismo tiempo como código cifrado de decadencia y corrupción del sistema político y como referencia implícita al colapso económico argentino y de su clase media. David Oubiña destaca en este contexto la estética claustrofóbica de la película y la ha decodificado como referencia a la caída de 
la clase media argentina (Oubiña 2004: 17). El cine de Martel es una nueva manera de recordar la historia política argentina en la pantalla. También podemos leer el cine de Martel como un "cine de la mirada" en el sentido de Gilles Deleuze. Los personajes principales de la película no son principalmente agentes de acción, sino que la mayoría de ellos son filtros visuales y táctiles. Martel utiliza esta práctica estética del cine moderno, conceptualizada por Deleuze, que no se centra en la acción sino en la experiencia sensual de los protagonistas. La primacía del sentido del tacto en las películas de Martel puede entenderse en este contexto como una subversión de la jerarquía tradicional de los sentidos. Otro elemento clave que Martel retoma de la estética del cine moderno, es la composición abierta que vamos a analizar más adelante en nuestra lectura de La ciénaga.

Menos transgresivo al nivel de su escritura fílmica es el cine de Lucía Puenzo. Su escritura cinematográfica es mucho más tradicional que la de Martel y de Carri, su cualidad subversiva se puede encontrar sobre todo en la elección del tema. En su película XXY (2007), que se centra en el tema de la transexualidad, plantea la cuestión del derecho a una doble identidad de sexo desde el punto de vista del joven Alex, que no quiere optar por una identidad sexual única en oposición a la biopolítica heteronormativa de la sociedad. Entre las directoras más exitosas del cine mexicano contemporáneo hay que mencionar: Dana Rotberg (Intimidad 1991) (Ángel del Fuego 1992), Busi Cortés (El secreto de Romelia 1988) (Serpientes y escaleras 1992) y María Novaro (Lola 1989) (Danzón 1991) (El Jardín del Edén, 1994). Mientras María Novaro hace un cine de los afectos femeninos que aborda el análisis y visualización de la vulnerabilidad femenina, Rothenberg se centra en una construcción subversiva del placer femenino y utiliza estrategias transgresivas para mostrar una sexualidad femenina más allá del discurso heteronormativo del cine convencional. Busi Cortés en su lugar se coloca en una tradición feminista clásica y se concentra en el tema de la complicidad de las mujeres como discurso fundamental de sus películas. Un ejemplo paradigmático del nuevo cine de mujeres de Brasil es la directora Tata Amaral con su trilogía, (Um Céu de Estrelas 1996) (Através de Janela 2000) (Antônia 2006) que se centra en la experiencia de las mujeres en las ciudades de Sao Paulo desde diversas favelas étnicas y sociales hasta la clase media. La pobreza, la violencia y el racismo son los obstáculos contra los que las protagonistas tienen que luchar en las favelas y que llegan a veces a superar a través de nuevas construcciones de identidad en los medios de la música cómo el hip-hop y el rap.

Incluso el país más joven de producción cinematográfica femenina, Chile, ya cuenta con una directora de fama internacional: Alicia Scherson. Scherson desarrolla en sus dos películas Play (2005) y Turistas (2009), un cine nómada, que mete en escena la búsqueda de identidad de las figuras femeninas de diferentes clases sociales. Nuevas perspectivas para el cine de mujeres se encuentran también en Perú. La directora peruana Claudia Llosa con su películas Madeinusa (2006) y La teta asustada (2009) proporciona un ejemplo excelente para los debates en curso sobre la cultura de la memoria subjetiva de las mujeres. Al igual que en la película de Lucrecia Martel, La niña santa, Madeinusa de Llosa construye la experiencia íntima de una niña atrapada en el conflicto entre sus deseos eróticos y un cultura católica represiva. Claudia Llosa ha llegado al éxito internacional con 
La teta asustada, película que fue premiada con el Oso de Oro en el Festival de Cine de Berlín. Aquí Llosa utiliza el medio cinematográfico para construir la memoria peruana de la guerra y muestra como esta memoria está inscrita como trauma en el cuerpo de las protagonistas femeninas. La protagonista intenta sobrevivir el trauma con la ayuda de un ritual indígena pre-moderno. Iniciando con el canto de la madre moribunda violada durante los años de terror, Llosa logra exigir la participación del espectador en la experiencia del trauma de su protagonista. Al final de la película la protagonista es capaz de deshacerse del trauma, puede quitarse la papa de la vagina que había utilizado para protegerse contra los violadores de su cuerpo y comienza una nueva vida más allá del miedo y el terror. El cine femenino latinoamericano experimenta con nuevas formas de percepción estética e inaugura un nuevo tipo de cine político.

En lo siguiente queremos concentrarnos en un análisis concreto de La ciénaga que se puede considerar como una obra maestra del nuevo cine argentino de mujeres. El cine de Lucrecia Martel se constituye según nuestro punto de vista como cine de transgresión por excelencia, cine que se complace en transgredir las normas académicas del realismo cinematográfico y del cine de acción tanto como los dispositivos tradicionales del cuerpo, del deseo y de la mirada.

El primer largometraje de la directora argentina, La ciénaga (2001), obtuvo el premio Alfred Baver en el festival de cine de Berlín y ha sido considerado por la crítica nacional e internacional como "uno de los puntos más altos del cine argentino contemporáneo" (Oubiña 2009: 92) y como trabajo que "llama la atención por su carácter radical y fronterizo" (Balagué 2011: 234). El mismo año Martel obtuvo una beca para seguir trabajando en el medio cinematográfico y pudo contar para su segundo largometraje La niña santa (2004) con la coproducción de la compañía de Agustín y Pedro Almodóvar El deseo. Su tercer largometraje es Mujer sin cabeza de 2008, película cuyo título hace voluntariamente referencia al cine de terror sin por eso inscribirse en la tradición del cine de género.

Queremos en lo siguiente concentrarnos sobre todo en el primer largometraje de Lucrecia Martel La ciénaga y tratar de poner de relieve algunos de los procedimientos transgresivos principales. Salen a la vista al menos dos estrategias básicas de transgresión:

1. Transgresión radical y voluntaria de las categorías académicas del cine de acción.

2. Subversión de la oposición binaria entre mirada subjetiva y objetiva y subversión de los dispositivos tradicionales del cuerpo y del deseo.

\section{Un cine de la mirada: "La ciénaga" como subversión del cine de la acción}

Empezamos con el primer punto: La ciénaga como subversión del clásico cine de acción. Es casi imposible resumir la acción de la película La ciénaga porque la acción no existe. Un grupo de burgueses de clase media, entre ellos dos mujeres, Mecha, una mujer de cincuenta años alcohólica y depresiva y su prima Tali junto con sus hijos y maridos se 
reúnen al borde de una sucia y putrefacta piscina de una casa colonial medio en ruinas en la provincia de Salta. No hacen nada, duermen, se emborrachan, miran la televisión que incesantemente estrena reportajes aburridos sobre las supuestas epifanías de la virgen en la provincia de Salta. No pasa nada, los personajes parecen prisioneros malditos, desgraciados, abandonados para siempre en una ciénaga infinita. Son dos caídas las que constituyen el marco de la película y que tienen la función de prólogo y epílogo: en el prólogo vemos a Mecha, la dueña de la casa, borracha cayéndose sobre las copas de cristal al borde de la piscina, en el epílogo vemos al hijo más joven de Tali, el pequeño Luciano, que se muere al caer de una escalera intentando ver al otro lado del patio donde creía que había un perro monstruoso en forma de rata africana.

La ciénaga es una película bekettiana por excelencia, todos parecen esperar algo, pero no pasa nada en absoluto. La ciénaga es el contrario del cine de acción. La acción no existe. Los cuerpos aparecen agotados, heridos, tumbados al borde de la piscina con agua sucia y podrida. (Véanse fotograma $n^{\circ} 1$ y 2 )

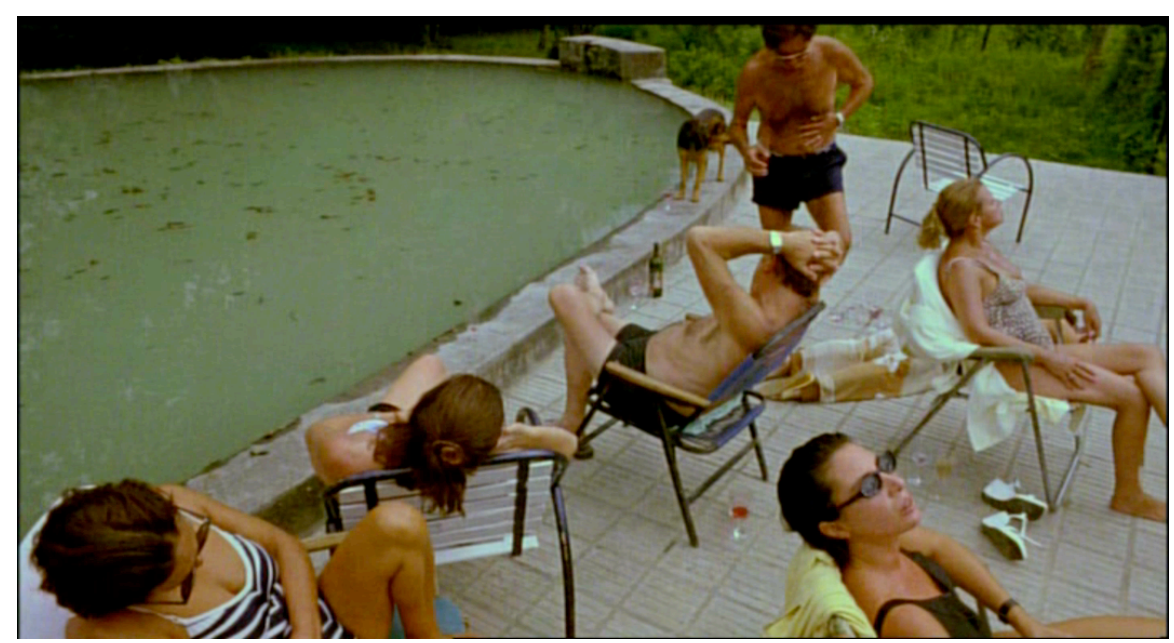

Fotograma n¹: Lucrecia Martel: La ciénaga (00.04.56)

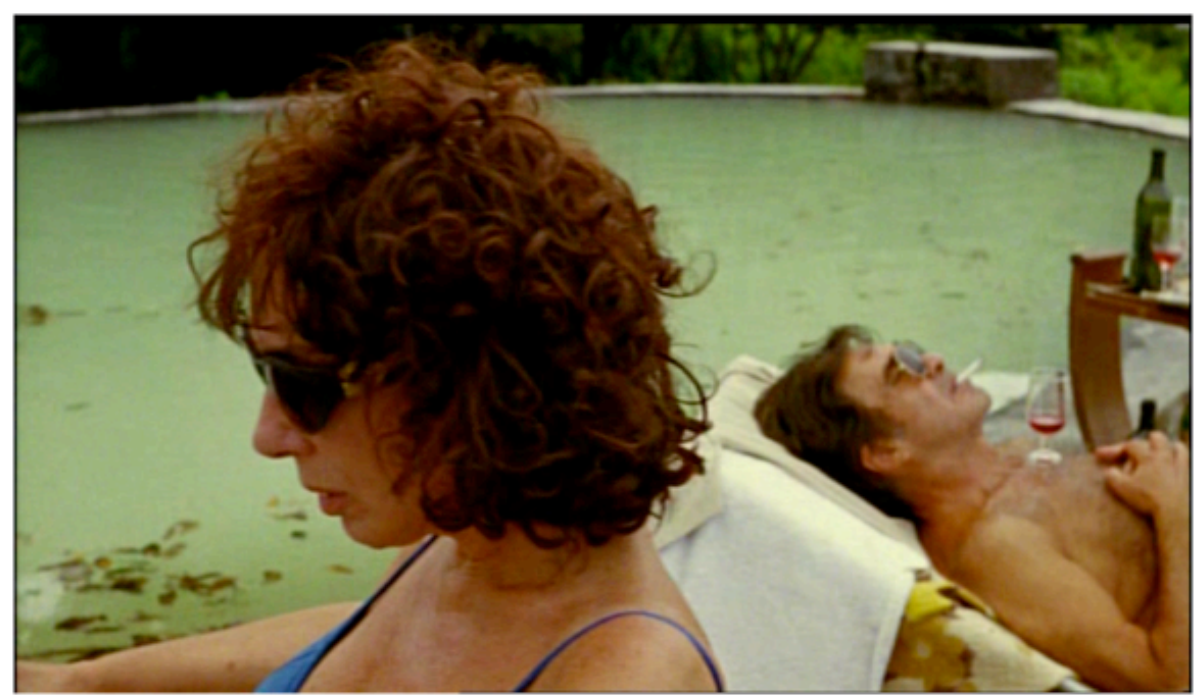

Fotograma n²: Lucrecia Martel: La ciénaga (00.02.51) 
Lo podrido como categoría sensual de percepción tanto como métafora de decadencia y crisis económica de la clase media constituye el hilo conductor de la película. Pero lo podrido no es solo una simple metáfora del estado decadente de la clase media, sino que tiene también un significado metafímico y autoreflexivo en tanto que afecta a la estructura fílmica misma. En vez de presentarnos una trama lineal con inicio, nudo y desenlace tan habitual en el cine de acción tradicional, Martel rechaza voluntariamente el concepto de trama lineal y nos confronta con una textura visual laberíntica y borgesiana en la que varios senderos se bifurcan sin llevarnos jamás a ningún centro. Martel misma constata en este contexto: "Lo que no me gusta de las tramas [...] es que hay una evolución [...] y yo no he visto un acontecimiento en mi vida que tenga un inicio, un nudo y un desenlace" (Martel cit. por Oubiña 2009: 27).

Recurriendo a posiciones de David Oubiña y Kristin Thompson' podemos denominar la textura laberíntica adoptada por Martel en La ciénaga una textura de exceso, un cinematic excess, una "textura visual que se orienta hacia lo discontinuo y que se resiste a comparecer ante el sistema ordenado de representación" (Oubiña 2009: 25).

El espectador se pierde en esta textura laberíntica, sigue varios senderos que se bifurcan y que a veces parecen llevarle a un centro. ${ }^{2}$ Pero los supuestos centros se revelan continuamente como trampas que no contienen nada. Estos centros vacíos en torno a los que están organizados los senderos narrativos demuestran lo ruinoso y lo podrido de todo tipo de epistemología ya sea religiosa, materialista o fantástica.

Martel juega de un modo irónico con las ficciones católicas de la redención generadas por la epifanía de la virgen. Borracha, agotada por el calor y medio dormida, Mecha pasa su tiempo en la cama mirando absurdos documentales regionales en la televisión en las que se entrevistan testimonios sobre apariciones de la virgen en la provincia de Salta donde se desarrolla la acción. Al final de la película, Momi, la hija adolescente de Mecha, sale de repente en busca de algo. Vuelve inmediatamente diciendo a su hermana que le pregunta "¿Adónde fuiste?": "Fui adonde dijeron que apareció la Virgen. No vi nada."

La redención por la virgen se revela como trampa. En el laberinto de Martel no existe ni centro ni salida. La película cierra como ha empezado con la imagen de una piscina con agua podrida. (Véase el fotograma $n^{\circ} 3$ )

\footnotetext{
1 Kristin Thompson, "The concept of cinematic excess" cit. por Oubiña 2009: 25.

2 Véase en este contexto el término "mind-game-film" que utilizan Thomas Elsaesser y Sabine Schlickers para su análisis de películas que disponen de una estructura laberíntica y exigen un espectador implícito. (Elsaesser 2009: 13-41, Schlickers 2012: 300)
} 


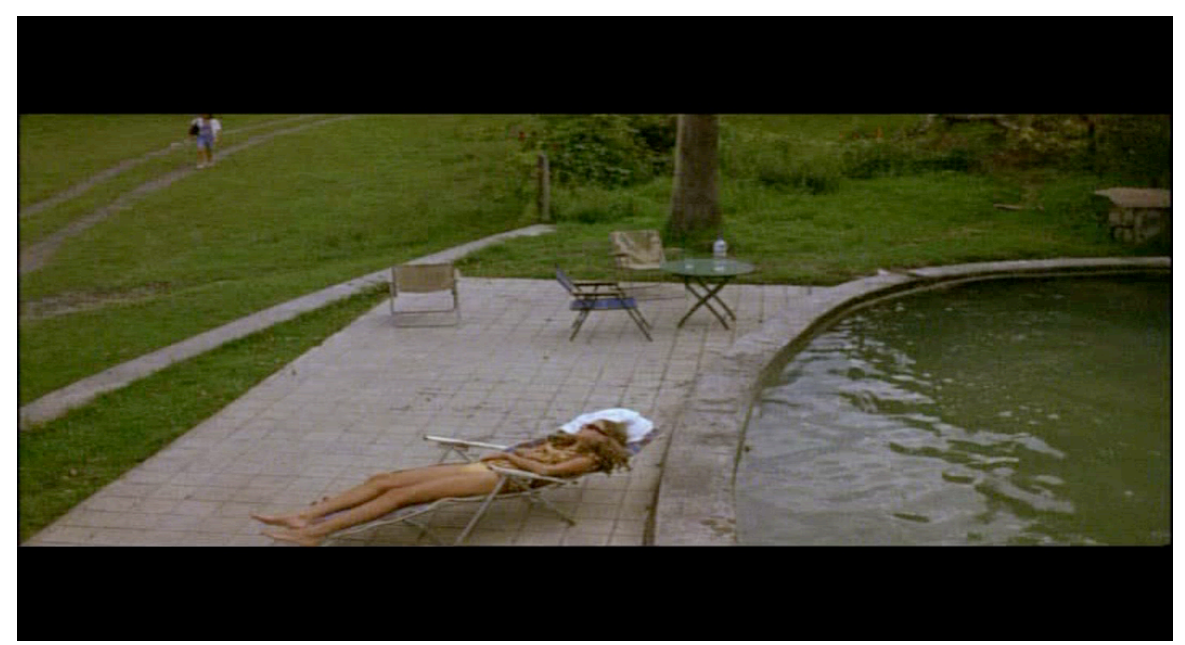

Fotograma n 3: Lucrecia Martel: La ciénaga (01.32.11)

La directora ha propuesto en este contexto una lectura existencialista de la película: "Es como si una criatura hubiera sido lanzada a la vida y ya nadie más se hiciera cargo de ella. Tengo una visión muy católica sobre este asunto (aunque soy atea, mi formación es católica), que proviene de la idea del desamparo divino: siento como si Dios hubiera creado la humanidad y luego se hubiera olvidado de ella, se hubiera ido. Entonces todos estamos como niños desamparados, en medio de una humanidad [...] donde nadie puede cuidar a nadie" (Martel 2002: 17).

La crítica reciente también ha puesto de relieve la dimensión existencialista de la película proponiendo una lectura filosófica: "En un plano más filosófico y metafísico, la película trata de la cuestión ética sobre la fragilidad de la existencia de los personajes" (GutiérezAlbilla: 2011,26$)$.

Si la epistemología religiosa ya no conduce a ninguna parte, la epistemología capitalista tampoco lo hace. Las mujeres, Mecha, alcohólica y frustrada y su prima Tali sueñan todo el tiempo con un viaje consumista a Bolivia para comprar ropa barata. Pero el viaje nunca se realiza. Todos están demasiado borrachos, demasiado cansados, demasiado agotados para hacer algo.

Otra epistemología negada radicalmente es la de un "realismo mágico", etiqueta según la directora "tan a mano para cualquier producto de cultura latinoamericana" (Martel cit. por Rich 2011). Martel misma rechaza esta etiqueta: "Rechazo esa etiqueta porque sugiere que hay algo, una realidad, sobre la que viene a aplicarse algún tipo de magia. Rechazo completamente esa idea" (ibid). Lo mágico-fantástico se revela en La ciénaga como otro centro-trampa. Luciano, el hijo menor de Tali, sueña con un perro-rata que según sus fantasías se encuentra al otro lado del patio de la casa. Al final de la película sube una escalera para ver el monstruo. Cae al otro lado y muere.

En La ciénaga no hay epifanía de vírgenes ni magia de ratas africanas. El centro está vacío. El accidente de Luciano al final de la película se corresponde con el accidente de Mecha al inicio de la película. Son los únicos acontecimientos en La ciénaga, pero no son 
acontecimientos que provocan un cambio. Al contrario: Todo sigue igual, todo es afectado por una estructura repetitiva que circula entorno a centros vacíos.

Otro ejemplo del gusto de Martel de jugar con la estructura del centro vacío lo constituye la anti-epifanía de la vaca podrida en la ciénaga. Mientras que los padres se emborrachan o se tiñen el pelo, los niños juegan salvajemente con sus pistolas en el bosque. De repente se asustan por la aparición de una vaca podrida en medio de La ciénaga. El gran plano de la enorme vaca podrida tiene la función de un drama-óptico que escenifica una anti-epifanía y que reenvía al gran plano del monstruoso pez podrido, escenificación grotesca de la ausencia de Dios al final de La dolce vita de Federico Fellini. (Véanse fotogramas $n^{\circ} 4$ y 5 ).

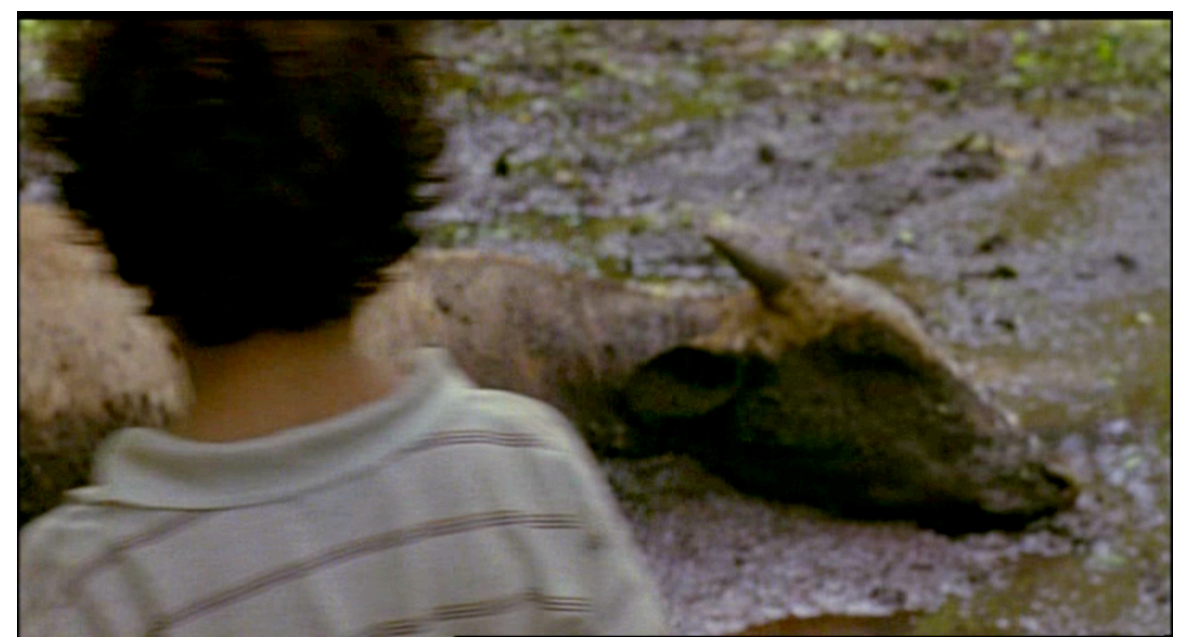

Fotograma n4: Lucrecia Martel: La ciénaga (00.33.40)

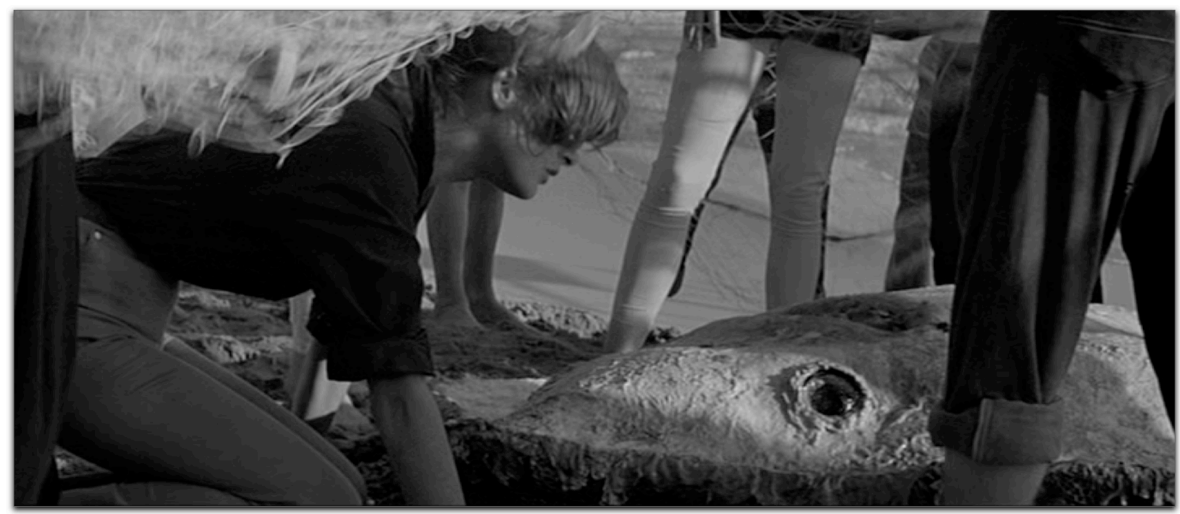

Fotograma n5: Federico Fellini: La dolce vita (02.44.02)

Lo fascinante en el cine de Martel es que haya una perfecta correlación entre el significado filosófico-existencial del estado de los protagonistas abandonados y desorientados en un mundo sin Dios y la estética fílmica de la mirada a este mundo. Martel opta por una mirada frágil y desorientada de una adolescente que mira al mundo. La cámara misma se transforma en cuerpo de la mirada frágil y desorientada que secciona todo a su alrededor. La percepción de la adolescente del mundo de los adultos borrachos con sus cuerpos feos y grotescos llenos de grasa y cicatrices se manifiesta sobre 
todo en las primeras imágenes de la película que constituyen un perfecto ejemplo de la disolución entre mirada objetiva y subjetiva. En este contexto La ciénaga también nos ofrece la posibilidad de ser leída como una celebración de la caída de la ley patriarcal: el padre de familia es nada más que un payaso borracho ocupado por teñirse constantemente el pelo. ${ }^{3}$

\section{Cuerpo, deseo y mirada en "La ciénaga"}

Hemos pasado ya al segundo y último punto de nuestro análisis: La ciénaga como ejemplo de subversión de la diferenciación entre mirada subjetiva y objetiva y como subversión de los dispositivos tradicionales del cuerpo y del deseo.

Ya hemos constatado que La ciénaga se constituye como cine anti-narrativo por excelencia y subvierte las normas académicas del cine de acción. Martel misma ha constatado en este contexto: "A mí no me interesa en absoluto contar historias. Pero sí me interesa percibir un proceso" (Martel cit. por Oubiña 2009: 81).

En vez de narrar, el cine de Martel observa, es un "cine de vidente" (Deleuze 1986: 13), un "cinéma de voyant" en el sentido de Gilles Deleuze, un cine que se inscribe en la tradición del cine moderno representado entre otros por Michelangelo Antonioni, Jean-Luc Godard, Chantal Akerman, Agnès Varda y Catherine Breillat. Este tipo de cine moderno se puede definir como cine de exceso en el que proliferan los acontecimientos visuales.

Las protagonistas del cine moderno de la mirada - siempre según los conocidos teoremas de Deleuze - ya no son protagonistas activas que accionan de algún modo, sino que se han transformado en espectadores. El espectador real es entonces un voyeur de segundo plano que observa a un protagonista que observa.

Es un cine de vidente, ya no es un cine de acción. [...] ahora la identificación se invierte efectivamente: el personaje se ha transformado en una suerte de espectador. Por más que se mueva, corra y se agite, la situación en que se encuentra desborda por todas partes su capacidad motriz y le hace ver y oír lo que en derecho ya no corresponde a una repuesta o a una acción. Más que reaccionar, registra (Deleuze 1986: 13).

Lo original de Martel consiste en instalar la mirada de una adolescente como mirada principal y filtro de percepción con el que el espectador tiene que identificarse sin saber a

\footnotetext{
3 Véase en este contexto el excelente análisis de Gonzalo Aguilar que constata que justamente la desintegración y la caída del orden patriarcal que demuestra la película permite la posibilidad de una observación fílmica desde el imaginario femenino: "The society organized around patriarchal authority, with all that this implies, disintegrates in these films, testifying to the shift from a masculine imagination (which dominated human life for centuries) to a feminine imagination in film." (Aguliar 201 1: 39)
} 
quien pertenece esta mirada. ${ }^{4}$ En torno a la función subjetiva de la cámara Martel declara:

La cámara es un personaje con el que me siento muy identificada. Siempre es alguien que pertenece al mundo de lo narrado. [...] Lo que se ve no puede ser algo mirado por nadie; aunque no es ningún personaje en particular, la cámara es alguien. [...] el personaje que observa [...] tiene una curiosidad que le permite suspender el juicio moral" (Martel cit. por Oubiña 2009: 77).

Al funcionalizar la mirada femenina como filtro de percepción Martel se inscribe en la tradición del cine de Antonioni que había declarado que las protagonistas de sus películas son un filtro de percepción ${ }^{5}$ y en la tradición del cine de Catherine Breillat que también ha utilizado la mirada femenina de una adolescente como filtro de percepción en su primer largometraje Une vraie jeune fille (1976). ${ }^{6}$ La mirada en La ciénaga es subjetiva y objetiva a la vez y deconstruye a la manera del "style indirecte libre" de Flaubert la posibilidad de una diferenciación entre mirada interior y exterior.

Según los conocidos conceptos de Deleuze la indescernibilidad entre mirada subjetiva y mirada objetivo constituye una estrategia central de la poética del cine moderno:

En cuanto a la distinción entre subjetivo y objetivo, también va perdiendo importancia a medida que la situación óptica o la descripción visual reemplazan a la acción motriz. Se cae en un principio de indeterminabilidad, de indiscernabilidad: ya no se sabe qué es lo imaginario o lo real, lo físico o lo mental en la situación [...] (Deleuze 1986: 13).

La percepción de la adolescente con la que la película nos confronta es una percepción que deforma voluntariamente los dispositivos corporales. En vez de ofrecernos cuerpos burgueses normalizados, nos ofrece cuerpos fragmentados. (Véanse fotogramas $n^{\circ} 6$ al 8).

La fragmentación de los cuerpos presentados no es solo una estrategia visual de la mirada femenina, sino también una de las categorías centrales del deseo erótico que fragmenta el cuerpo en sus partes deseables.

4 Véase en este contexto el análisis de Jens Andermann que constata la falta voluntaria de "establishing shots" en La ciénaga y su opción por "a mobile and uncertain web of permeable enclosures" (Andermann 2012: 8081).

5 Véase Antonioni 2005: 303.

6 Véase en este contexto: Felten 2011. 

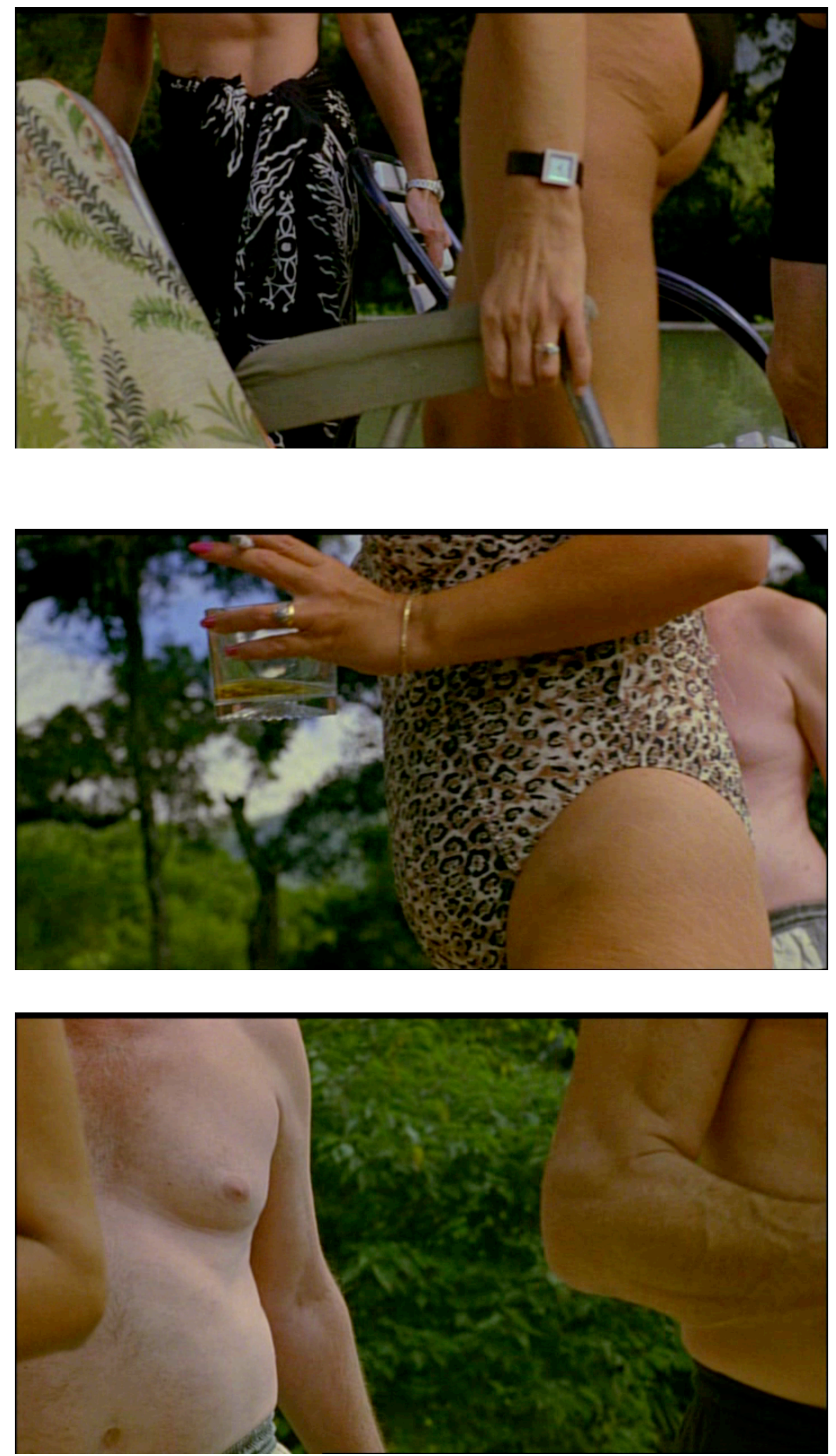

Fotograma n 6-8: Lucrecia Martel: La ciénaga (00.01.21) 
El deseo erótico está omnipresente en La ciénaga y transgrede voluntariamente las normas habituales que separan las clases sociales y las familiares. Se podría decir según Oubiña que La ciénaga es: "un filme sobre camas. Todos se meten entre las sábanas de otros: Momi en la cama de la sirvienta y en la cama de Vero; Vero en la cama de José, José y Joaquín en la cama de Mecha [...]" (Oubiña 2009: 46-47). (Véanse fotogramas nº y 10).

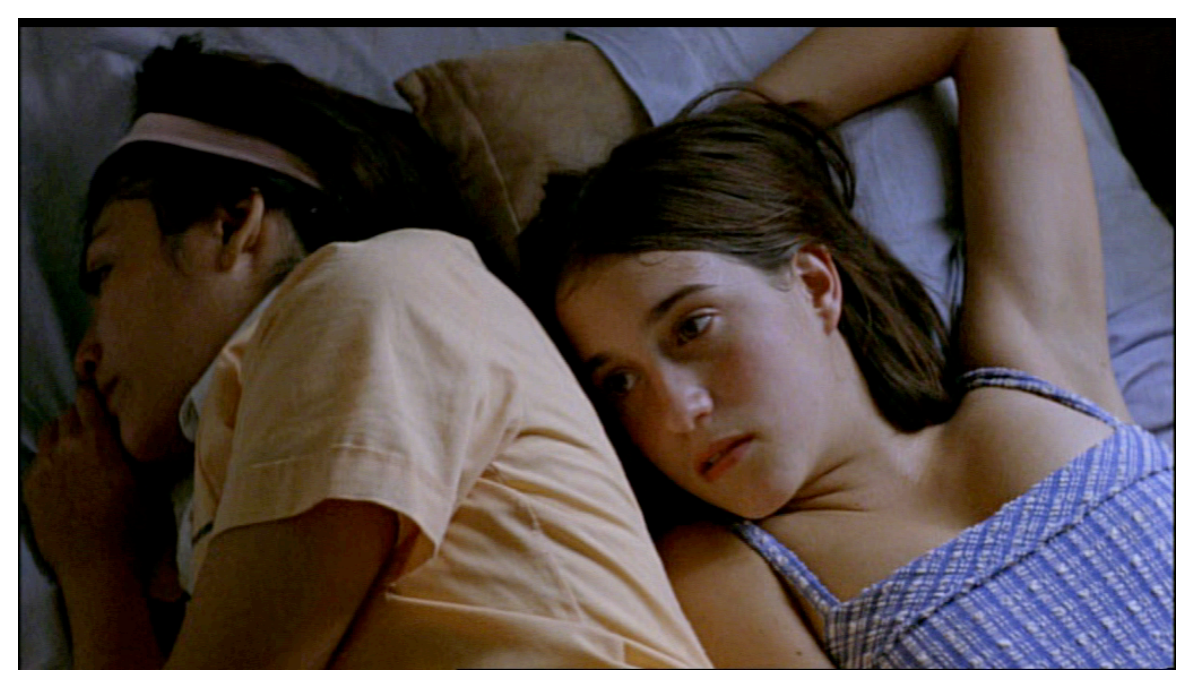

Fotograma n9: Lucrecia Martel: La ciénaga (01.20.57)

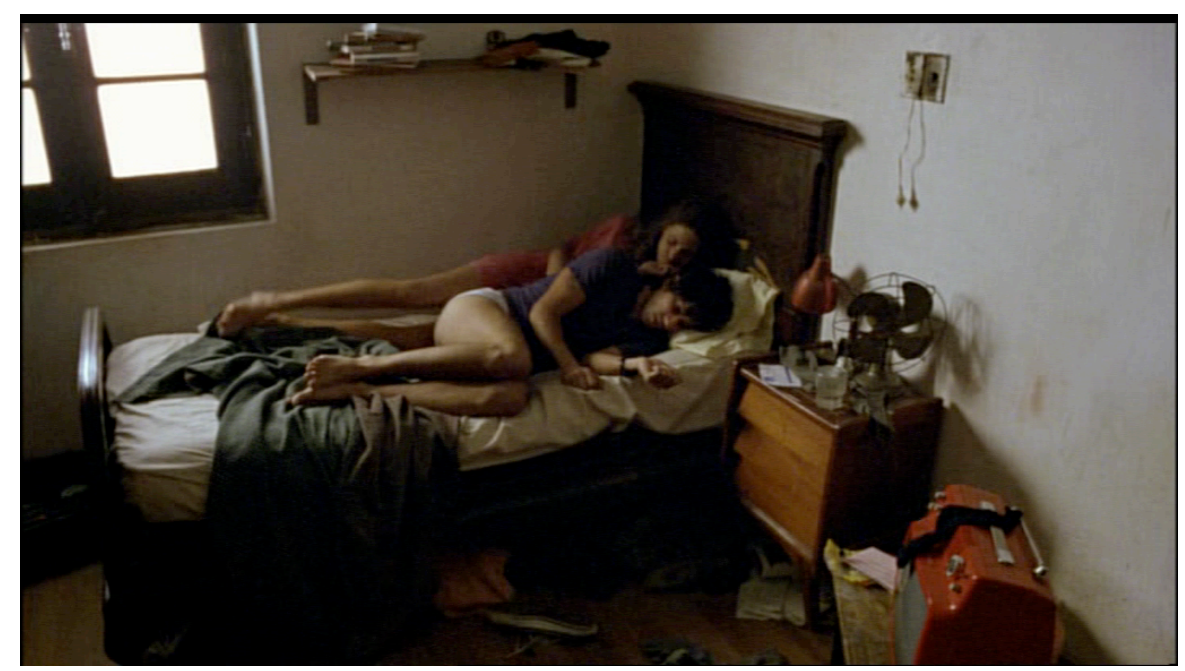

Fotograma n¹0: Lucrecia Martel: La ciénaga (01.01.45)

José, el hijo de Mecho, tiene la función de un oscuro objeto de deseo de todos y todas. Cuando vuelve borracho y herido de la fiesta de carnaval, las primas lo desvisten transformándolo en el "Cherubino" de sus deseos.

Lucrecia Martel misma ha constatado en este contexto: "[...] el deseo está siempre que hay un grupo de gente, así se trate de quienes estén o no unidos por la sangre; el deseo es algo que fluye, no necesita la concreción del acto sexual, pero circula y evitarlo es una actitud de muy clase media [...]" (Martel en Aguzzi 2001:27). 
El deseo transgresivo que se manifiesta en La ciénaga es un deseo fluyente y omnipresente que ignora las diferenciaciones binarias del sexo hetero-normativo tal como las normas habituales que separan dueña y sirviente, hermano y hermana, primo y prima y declara una cultura postpatriarcal del cuerpo. 


\section{BIBLIOGRAFÍA}

AguILAR, Gonzalo. New Argentine Film. Other Worlds, Palgrave Macmillan, New York, 2011.

Aguzzl, Juan. "El deseo es algo que fluye; evitarlo es un actitud muy clase media. Entrevista con Lucrecia Martel", El Eclipse, ano 3, № 4, (2001) p. 27.

AndermanN, Jens. New Argentine Cinema, Tauris, London/New York, 2012.

ANTONIONI, Michelangelo. Fare un film è per me vivere. Scritti sul cinema, Marsilio, Venezia, 2005

BALAGUÉ, Carles. El cine latinoamericano. Las grandes películas, Ediciones JC, Madrid, 2011.

Deleuze, Gilles. La imagen-tiempo. Estudios sobre cine 2. Barcelona/ Buenos Aires, Ediciones Paidós, 1986.

ElSAESSER, Thomas. "The Mind-Game-Film". En: Buckland, Warren (ed.): Puzzle Films. Complex Storytelling in Contemporary Cinema, Wiley Blackwell, Malden, 2009, pp. 13-41.

FELTEN, Uta. "Representaciones del cuerpo femenino en el cine de Catherine Breillat". En: Zurián, Francisco (ed.): Imágenes del eros. Género, sexualidad, estética y cultura del audiovisual, ocho y medio libros de cine, Madrid, 2011, pp. 46-55.

Felten, Uta. "The Headless Woman". En: Maurer Queipo, Isabel (ed.): Directory of World Cinema. Latin America, intellect, Bristol, 2013a, pp. 204-6.

FELTEN, Uta. "La niña santa". En: Maurer Queipo, Isabel (ed.): Directory of World Cinema. Latin America, intellect, Bristol, 2013b, pp. 206-8.

FELTEN, Uta. "La ciénaga". En: Maurer Queipo, Isabel (ed.): Directory of World Cinema. Latin America, intellect, Bristol, 2013c, pp. 214-15.

GutiéRrez-AlBilla, Julián Daniel. "Filmar desde lo femenino. Realismo subjetivo, desintegración y afecto corporal en La ciénaga de Lucrecia Martel". En: Zurián, Francisco (ed.): Imágenes del eros. Género, sexualidad, estética y cultura del audiovisual, ocho y medio libros de cine, Madrid, 2011 , pp. 15-34.

JAGOE, Eva-Lynn/CANT, John. "Vibraciones encarnadas en La niña santa de Lucrecia Martel". En: Rangil, Viviana (ed.): El cine argentino de hoy: entre el arte y la política, Biblos, Buenos Aires, 2007, pp. 170-182.

MARTEL, Lucrecia. "He sentido mucho dolor haciendo La ciénaga". En: Kinetoscopio 61 (2002), pp. 14-17. 
OUBIÑA, David. "Entre la ruptura y la Tradición: El reciente Cine Argentino". En: Los sentidos de Cine 31 (abril-junio de 2004), pp. 17-31.

OuBIÑA, David. Estudio crítico sobre „La ciénaga", Picnic Editorial, Buenos Aires, 2009.

RANGIL, Viviana. Otro punto de vista: mujer cine y en la Argentina. Beatriz Viterbo, Rosario, 2005.

RICH, B. Ruby. "Making Argentina matter again", New York Times, 30.09.2011.

SCHLICKERS, Sabine. "La narración perturbadora en el cine argentino del siglo XXI". En: Bongers, Wolfgang (ed.): Prismas del cine latinoamericano, Alfabeta, Santiago de Chile, 2012, pp. 277-302. 